\title{
PERANAN TINDAK TUTUR DALAM SENI PERTUNJUKAN KETOPRAK
}

\author{
Agus Rinto Basuki \\ Jurusan Pedalangan, Fakultas Seni Pertunjukan, \\ Institut Seni Indonesia Denpasar, Indonesia.
}

\begin{abstract}
Ketoprak performance can be determined by many aspects, i.e. : player, musician, director, dialogue, etc. To get the meaning of what are spoken by speakers (players) is needed to avoiding of miss interpretation, rigidity or stiff. The speech act analysis is one way to understanding them. The same goes for what are spoken by speakers (players) may be different from the speech acts. The speech act 'announcement' not only having the meaning 'announcement' but also can be 'ordering' or 'warning', on the contrary 'threatening'. According to Austin, a speech not only used to saying something, but also to doing something. Thus, the speech act is a speech having meant an action. This research will discuss the important of speech act in the art performance that used dialogues.
\end{abstract}

Keywords: Ketoprak, speech acts, and pragmatic rules.

Ketoprak sebagai salah satu kesenian daerah Jawa Tengah (khususnya), telah mampu mengundang banyak penonton dan pendengar di pelbagai pelosok pulau Jawa. Hal ini disebabkan oleh penampilan ketoprak sebagai 'teater tradisional', dapat menggambarkan cerita yang telah berakar, berdasarkan keteladanan yang luhur bangsa Indonesia pada masa silam, dan merupakan refleksi kehidupan sehari-hari bagi masyarakat Jawa khususnya.

Bahasa yang digunakan dalam ketoprak dapat mengakrabkan situasi dengan masyarakat penonton. Kenyataan ini tampak berbagai pertunjukan, baik melalui panggung, radio, maupun televisi, merupakan salah satu unsur yang memiliki peranan sangat dominan. Oleh karena itu, bahasa ketoprak merupakan repertoar yang sangat menarik untuk diteliti, terutama yang menyangkut penggunaan bahasa, atau dalam kajian ini difokuskan pada segi tindak tutur.

Menurut Austin (dalam Levinson, 1983:236) ${ }^{22}$ JL. Austin adalah seorang filosof berkebangsaan Inggris, ia merupakan orang pertama yang menyatakan bahwa terdapat banyak hal yang dapat dilakukan dengan katakata. Pandangannya yang paling mendasar tercermin dalam kuliah- 
kuliahnya, yang terkumpul menjadi sebuah buku yang diberi judul How to Do Things with Words.

Austin mengamati bahwa tuturan-tuturan itu tidak saja dipakai untuk melaporkan sesuatu kejadian, tetapi dalam hal-hal tertentu, tuturan itu harus diperhitungkan sebagai sebuah pelaksanaan tindakan (actions).

Penelitian ini bertujuan antara lain: a) Mendeskripsikan berbagai bentuk tindak tutur dalam ketoprak, b) Mendeskripsikan beberapa konteks tuturan, dan c) Mengetahui fungsi tindak tutur dalam ketoprak. Penelitian ini memiliki dua manfaat, yaitu manfaat teoretis dan manfaat praktis. Manfaat teoretis penelitian ini akan diwujudkan dalam bentuk khasanah teori Seni dan teori Linguistik, khususnya tentang teori tindak tutur yang bertipe kesenian panggung (ketoprak, wayang, ludruk, kentrung, dan sebagainya). Manfaat praktis dari penelitian ini dapat dimanfaatkan oleh para peneliti bidang seni budaya, yang memfokuskan pada masalah kebahasaan. Diharapkan pula, hasil dari penelitian ini dapat menopang pengetahuan para seniman panggung, untuk lebih memperhatikan kaidah-kaidah linguistik (pragmatik), daripada kaidah-kaidah konvensional.

Beberapa teori yang dijadikan ancangan dalam penelitian ini antara lain: a) Semantik dan Pragmatik, b) Konteks, dan c) Pra anggapan, Implikatur dan Inferensi. Semantik berbeda dengan Pragmatik, meskipun keduanya memandang bahasa dari segi makna. Semantik memandang bahasa menurut makna leksikal, yang terpisah dari situasi dan konteks. Dengan kata lain, memandang makna bahasa yang bebas konteks (context independent). Pragmatik memandang makna bahasa menurut pemakainya, yang terikat oleh situasi dan konteks (context dependent). Sehubungan dengan penelitian ini, penulis lebih menitikberatkan pada kajian pragmatik.

Istilah Konteks dipergunakan untuk mengacu pada pemahaman antar tokoh (penutur dengan mitra tutur), tentang pengetahuan, pengalaman, persoalan yang dipraanggapkan, situasi, waktu, tempat, dan peristiwa. Atau dengan kata lain, semua latar belakang yang berkaitan dengan pengetahuan penutur dan mitra tutur. Dengan demikian, konteks tidak hanya mengacu ungkapan secara verbal sebagai konteks lingual (cotext), tetapi juga mengacu pada beberapa hal yang ada di luar bahasa, sebagai konteks non lingual (context).

Makna pragmatik sebuah tuturan tidak selalu didapatkan dari tuturan yang sungguh-sungguh disampaikan oleh penutur. Dengan kata lain, makna yang tersurat dalam sebuah tuturan, tidaklah selalu sama dengan makna yang tersirat. Makna yang tersirat akan dapat diperoleh dengan mencermati konteks yang menyertai munculnya tuturan itu. Untuk dapat memahami sebuah konteks, diperlukan piranti yang berupa teori, yaitu ; Pra anggapan, Implikatur, dan Inferensi.

Secara umum, penutur selalu merancang pesan-pesan bahasanya berdasarkan asumsi-asumsi, yang sudah diketahui oleh mitra tutur. Tentu 
saja asumsi itu dapat salah, tetapi asumsi-asumsi itu mendasari banyak hal dalam penggunaan bahasa. Apa yang diasumsikan oleh penutur, sebagai hal yang benar atau hal yang diketahui oleh mitra tutur, dapat disebut sebagai pra anggapan (presupposition).

Sebuah tuturan dapat mengimplikasikan proposisi yang sebenarnya, bukan merupakan bagian dari tuturan tersebut, dan bukan pula merupakan konskwensi logis dari tuturan itu, itulah yang disebut dengan implikatur.

Inferensi atau kesimpulan sering harus dibuat sendiri oleh mitra tutur, karena dia tidak tahu apa makna yang sebenarnya yang dimaksudkan oleh penutur. Karena jalan pikiran penutur berbeda dengan mitra tutur, akan memungkinkan kesimpulan mitra tutur meleset, atau bahkan salah sama sekali. Apabila hal ini terjadi, maka mitra tutur harus membuat inferensi lagi. Dalam hal ini Gumperz (dalam Kartomihardjo, 1993:31) menganjurkan untuk lebih banyak menggunakan kesimpulan yang bersifat pragmatik, dan bukannya yang logis saja.

\section{METODE PENELITIAN}

Penelitian ini dikategorikan sebagai penelitian eksploratif, yaitu menggali sedalam-dalamnya, dengan tujuan untuk mencari masalah-masalah baru, yang selanjutnya masalah tersebut dibahas secara cermat. Dengan demikian, maksud dari penelitian ini adalah penggalian tentang tindak tutur, yang terdapat di dalam seni pertunjukan ketoprak. Selain itu, penelitian ini juga bertipe kualitatif, yang akan tampak dari pemerolehan data, pengumpulan data, analisis data, dan penyajian hasil analisis data (Muhadjir, 1990:126-130).

Data penelitian ini berbentuk penggunaan bahasa (language used), baik dalam bentuk pergelaran ketoprak, maupun berasal dari rekaman ketoprak. Sumber data penelitian ini adalah pita suara yang memuat rekaman ketoprak. Data tersebut ada yang berujud rekaman dari sebuah produsen pita suara, maupun rekaman pada waktu pertunjukan langsung.

Populasi dari penelitian ini adalah tiga buah cerita berbentuk pertunjukan langsung, dan enam buah cerita berbentuk rekaman dari produsen pita suara. Sampel dari penelitian ini dipilih berdasarkan Probability Sampling, dengan teknik Purposive Sampling. Maksud dari pengambilan sampel tersebut adalah sampel didapatkan dari suatu pertunjukan langsung yang telah terjadwal, dengan demikian dapat memilih cerita tertentu, dengan mempertimbangkan konsep tujuan penelitian. Sampel dari penelitian ini adalah: a) Labuh Tresna Sabaya Pati, b) Rara Mendut, dan c) Sutrisno-Waryanti.

Analisis data dalam penelitian ini dilakukan dengan menggunakan Metode Kontekstual.

HASIL ANALISIS DATA 
Deskripsi secara rinci akan menyangkut; konteks tuturan, bentuk tindak tutur, serta analisis tindak tutur dalam ketoprak. Dalam tulisan ini penulis tidak dapat menyajikan secara menyeluruh semua hasil analisis data, namun hanya beberapa yang dianggap mewakili.

\section{Tindak tutur 'Menguji' dan 'Meyakinkan'}

Konteks tuturan:

Bapa Ajar Sidikoro kedatangan seorang tamu (Sanggoro) yang juga mantan muridnya, tamu tersebut bermaksud melamar anaknya (Endang Mustikosari), karena dia sebagai bupati belum mempunyai isteri.

Bentuk tuturan:

Bapa Ajar:

$$
\begin{aligned}
& \text { "Nanging ngger, napa sampun dipunpenggalih } \\
& \text { dhawuh penjenengan punika, lan napa mboten } \\
& \text { getun keduwung ing tembe wingking. Awit anak } \\
& \text { kula namung sak endang wijiling padepokan, } \\
& \text { napa mboten nglorot asma kaluhuran } \\
& \text { panjenengan ndalem ngger?" } \\
& \text { (Tetapi nak, apa sudah dipikirkan masak-masak, } \\
& \text { dan apakah tidak kecewa di belakang hari. } \\
& \text { Karena anak saya hanya seorang endang yang } \\
& \text { lahir di padepokan, apa tidak akan menyuramkan } \\
& \text { nama baik anda ?) } \\
& \text { "Oh mboten, mboten bapa, kula mboten badhe } \\
& \text { getun. Sedaya menika sampun kula penggalih } \\
& \text { sak derengipun, sarta ingkang wigatos, } \\
& \text { minangka srana anggen kula atur sembulih } \\
& \text { dhateng panjenengan bapa" } \\
& \text { (Oh tidak, tidak bapa, saya tidak akan kecewa. } \\
& \text { Semua sudah saya pikirkan sebelumnya, serta } \\
& \text { yang paling penting sebagai sarana balas budi } \\
& \text { terhadap bapa). }
\end{aligned}
$$

Sanggoro: "Oh mboten, mboten bapa, kula mboten badhe

Analisis tuturan:

Bapa ajar tidak bermaksud menolak permintaan Sanggoro, meskipun bentuk tuturan tersebut seolah-olah menolak. Bapa ajar lebih bermaksud 'menguji' kesungguhan Sanggoro dalam melamar anaknya. Hal ini diperkuat dengan jawaban Sanggoro yang 'meyakinkan' tentang maksud kedatangannya. Dalam dialog ini terjadi dua tindak tutur, yaitu 'menguji' dan 'meyakinkan'. Sesuatu yang biasa terjadi, bahwa bila seseorang diuji atau disangsikan, maka 
akan muncul tindak 'meyakinkan' sebagai jawaban dari tindak 'menguji'.

\title{
2. Tindak tutur 'Menyuruh' dan 'Mengerjakan'
}

Konteks tuturan:

Akan diadakan pertemuan di padepokan Putatslawe, yang dipimpin oleh Bapa Ajar Sidikoro.

Bentuk tuturan;

Bapa Ajar:

\begin{abstract}
"Apa kanca rowangmu padha mlumpuk kabeh?" (Apa semua temanmu sudah berkumpul semua ?). "Sampun bapa resi, setunggal kemawon mboten wonten ingkang kecicir. Sedaya sampun sami nglempak, nyadhong dhawuh panjenengan bapa resi"

(Sudah bapa resi, tidak ada satupun yang tertinggal. Semua sudah berkumpul, siap menerima perintah paduka bapa resi).
\end{abstract}

Cantrik:

Analisis tuturan:

Bapa Ajar dalam dialog tersebut tidak bermaksud 'menanyakan', apakah peserta pertemuan sudah berkumpul semua. Namun lebih menjurus pada tindak tutur 'menyuruh' cantrik, untuk memastikan apakah semua peserta pertemuan sudah lengkap. Posisi bapa Ajar sebagai seorang resi tentu memiliki cara yang santun dalam 'menyuruh' bawahannya. Dalam hal ini, bapa ajar cukup menanyakan kelengkapan peserta pertemuan. Jawaban cantrik juga mengisyaratkan, bahwa cantrik tersebut telah betul-betul 'mengerjakan' semua perintah bapa ajar, yaitu memastikan peserta pertemuan semuanya telah hadir.

\section{Tindak tutur 'Permisi' dan 'Mempersilahkan'}

Konteks tuturan:

Sedang terjadi pertemuan antara bapa Ajar Sidikoro dengan para bawahannya, tiba-tiba kedatangan tamu yang sudah dikenal dengan baik.

Bentuk tuturan:

Sanggoro: "Kula ingkang sowan bapa resi"

(Saya yang datang bapa resi).

Bapa Ajar:

"Mangga den kula aturi lenggah"

(Mari den silahkan duduk).

Analisis tuturan:

Sanggoro sebagai mantan murid dari bapa Ajar menuturkan 'permisi' dengan cara cukup akrab, yaitu dengan mengatakan "kula ingkang 
sowan". Pada umumnya, seseorang yang akan masuk ke rumah orang lain, akan mengatakan "kula nuwun" (permisi), namun bila antara penutur dengan mitra tutur sudah cukup akrab, maka tindak tutur 'permisi' akan sangat lazim memakai "kula ingkang sowan". Bapa ajar dalam mempersilahkan tamunya juga dengan perkataan cukup akrab, yaitu langsung mempersilahkan duduk. Pada umumnya bagi tamu yang belum akrab akan dipersilahkan masuk dulu "mangga pinarak", baru kemudian dipersilahkan duduk. Perbedaan ini hanya terjadi pada tingkat keakraban antara penutur dengan mitra tutur.

\section{Tindak tutur 'Memaksa' dan 'Menolak'}

Konteks tuturan:

Bupati dari Mbarat (Hendronegoro) sudah tidak sabar mendengar jawaban Endang Mustikosari (anak bapa Ajar), yang meminta waktu sebulan untuk memberi jawaban atas lamarannya, dan meminta bapa ajar sekeluarga untuk boyongan ke Kadipaten.

Bentuk tuturan:

Hendronegoro:

"Wangsul kula dhateng kadipaten Mbarat
kedah saged mboyong yayi Endang
Mustikosari"
(Kepulangan saya ke kadipaten Mbarat harus
dapat memboyong dinda Endang Mustikosari).
"Ngger Bupati, kula namung saged
ngaturaken sewu sembah nuwun. Nanging
wonten ndalem sewu, dene kula mboten saged
minangkani pamundhutipun penjenengan,
jalaran kula dados mancakaki ingkang kedah
ngayomi para cantrik lan magersari, menawi
kula tilar tartamtu badhe buyar"
(Nanda Bupati, saya hanya dapat mengucapkan
beribu terima kasih. Tetapi maaf bila saya tidak
dapat mengabulkan permintaan anda, karena
saya sebagai tulang punggung, yang harus
melindungi para cantrik dan magersari, bila
kutinggalkan tentu akan berantakan).

Analisis tuturan:

Posisi Hendronegoro sebagai Bupati (penguasa) mempergunakan tindak 'memaksa' untuk mendapatkan Endang Mustikosari. Selain itu, waktu sebulan yang diberikan Endang Mustikosari tidak membuatnya sabar, justru ikut menentukan bupati untuk 'segera' mendapatkan Endang Mustikosari. Jawaban yang diberikan oleh bapa Ajar bukan untuk 'memberitahu' Bupati tentang tanggung jawabnya sebagai Ajar 
di padepokan, tetapi lebih merupakan 'penolakan' atas lamaran Bupati Hendronegoro. Orang Jawa yang mengerti sopan santun, tentu dalam menolak akan mengatakan "matur nuwun", bukan "ampun" (jangan) atau "mboten" (tidak).

\section{Tindak tutur 'Menuduh' dan 'Mengakui'}

Konteks tuturan:

Baru saja terjadi pembunuhan atas Bupati Hendronegoro di Kadipaten Mbarat, demikian pula terjadi pelepasan tali ikatan pada bapa Ajar Sidikoro. Hendrawati bingung mencari siapa pelakunya.

Bentuk tuturan:

Hendrawati: "He sapa kowe?, ngakua sak durunge tak pateni !"

(Hai siapa kamu ?, mengakulah sebelum aku bunuh !)

Sanggoro: “Jenengku Sanggoro, Bupati saka Jogorogo, lha sapa kowe?"

(Namaku Sanggoro, Bupati dari Jogorogo, lantas siapa kamu ?)

Hendrawati: "Aku Hendrawati, kadange kangmas Hendronegoro. Sanggoro! kowe sing ngluwari bandane Ajar Sidikoro?" (aku Hendrawati, adiknya Hendro. Sanggoro !, apa kamu yang melepas tali ikatan Ajar Sidikoro ?).

Sanggoro: "Iya" (ya).

Analisis tuturan:

Kekalutan Hendrawati atas kematian kakaknya, membuatnya gelap mata dalam menentukan siapa pelaku pembunuhan kakaknya, dan pelaku yang melepaskan tali ikatan bapa Ajar. Karena kebetulan yang berada saat itu adalah Sanggoro, maka dengan serta merta Hendrawati menuduh Sanggorolah pelaku yang melepas tali ikatan bapa ajar. Sanggoro adalah seorang yang cukup jujur, buktinya mengakui tuduhan yang dilontarkan Hendrawati. Orang yang tertuduh hanya mempunyai dua pilihan, yaitu mengakui atau mengelak.

\section{Tindak tutur 'Merayu' dan 'Menolak'}

Konteks tuturan:

Waryanti bertemu dengan Tosidono (salah satu prajurit dari Tanjunganom), pertemuan tersebut membuat Tosidono tertambat hatinya terhadap Waryanti. 
Bentuk tuturan:

Tosidono :

"Jenengmu ngeget-geti Waryanti, cocok karo Tosidono"

(Namamu mengejutkan Waryanti, cocok dengan

Tosidono).

Waryanti : "E e cocok kepriye?"

(E e cocok bagaimana ?).

Tosidono :

"Sing wedok ayu sing lanang manis"

Waryanti : "Tak rasak-rasakke kok kepethuk wong edan ta iki ?"

(Aku rasa-rasakan bertemu orang gila ini).

Analisis tuturan:

Ucapan yang disampaikan Tosidono "cocok karo Tosidono" dan "sing wedok ayu sing lanang manis", merupakan usaha mempengaruhi Waryanti agar hatinya menerima rayuan Tosidono. Dalam kisah ini Tosidono digambarkan sebagai laki-laki yang wajahnya tidak tampan (berbadan pendek, berkulit hitam), namun Tosidono mengatakan "sing lanang manis", jadi bertolak belakang dengan keadaan yang sesungguhnya. Waryanti dengan serta merta menolak rayuan gombal Tosidono, dengan mengatakan "kepethuk wong edan". Dengan mengatakan seperti itu mengisyaratkan bahwa Waryanti hanya menganggap Tosidono setaraf dengan orang gila. Jadi secara pragmatis Waryanti telah menolak rayuan Tosidono, atau telah melakukan tindak tutur 'menolak'.

\section{Tindak tutur 'Meminta Pendapat' dan 'Merekomendasi'}

Konteks tuturan:

Tumenggung Wiroguno bingung memikirkan rara Mendut yang masih belum mau menerima cintanya, padahal Rara Mendut sebagai putri boyongan.

Bentuk tuturan:

T. Wiroguno: "Penggalihku ki lak buneg ta, mung menggalih Mendut kok wangkal ki piye ta nalare?"

(Pikiranku sedang bingung, hanya memikirkan Mendut yang masih berkeras hati, bagaimana sebaiknya).

Wirojoyo:

“.... Menika menawi kula lho ndara nggung, inggih kedahipun dipunrangkepi, inggih dipuntamani ngangge aji semar mesem, menapa inggih aji jaran goyang........bilih menawi mboten luluh isih puguh, inggih rehning wonten katumenggungan menika rak gadhah panguwaos".

(.......Ini kalau menurut pendapat saya ndara nggung, mestinya dibekali, diguna-guna dengan aji semar mesem atau aji jaran goyang.......kalau masih berkeras hati, ya 
karena anda di katumenggungan ini kan memiliki kekuasaan).

Analisis tuturan:

Tumenggung Wiroguno dengan tuturannya bermaksud meminta pendapat kepada bawahannya tentang cara mengatasi rara mendut, yang masih belum mau menerima cintanya. Wirojoyo sebagai abdi yang setia 'merekomendasikan' dua cara dalam mengatasi rara Mendut. Pertama, agar memakai cara-cara licik, yaitu dengan mengguna-guna dengan ajian Semar Mesem dan atau ajian Jaran Goyang $^{2}$. Ke dua, dengan memakai cara kekerasan, karena kedudukan Wiroguno sebagai Tumenggung, maka sangat memungkinkan memakai cara-cara kekerasan, atau dengan cara memaksa. Wirojoyo 'merekomendasikan' untuk memakai cara yang pertama, dan diharapkan akan luluh hatinya, namun bila masih keras hatinya, maka Wirojoyo 'merekomendasikan' untuk memakai cara yang ke dua, yaitu dengan kekerasan atau paksaan.

\section{Tindak tutur 'Menawarkan' dan 'Menolak'}

Konteks tuturan:

Sanggoro tidak mau mengalah dengan Sidarto, tentang lamarannya terhadap Endang Mustikosari. Untuk itu Sanggoro bermaksud mencarikan wanita lain sebagai gantinya.

Bentuk tuturan:

Sidarto:

Sanggoro:

"Panjenengan sampun jumeneng Bupati, upamia ngupadi garwa langkung gampil panjenengan ketimbang kula kangmas"

(Anda sudah menjadi bupati, seandainya mencari jodoh lebih mudah anda daripada saya kangmas).

"Ya pancen bener Sidarto. Akeh para wanita kepengin dadi garwaku, athik rupane ayu-ayu. Nanging kabeh mau ora ana sing bisa uju rasane penggalihku. Yen endang putrane sapa, yen putri putrane ratu ngendi. Aku sing saguh ndhodhog lawange nginang jambe suruh"

(Ya memang benar Sidarto. Banyak para wanita yang ingin menjadi istriku, wajahnya cantik-cantik. Tetapi semua itu tidak ada yang menarik hatiku. Kalau endang anaknya siapa, kalau putri anaknya raja mana, aku yang akan melamarkan).

Sidarto: "Matur nuwun kangmas, nanging pilihan kula mboten sanes kejawi yayi Endang Mustikosari"

(Terima kasih kangmas, tetapi pilihan saya tidak lain hanya dinda Endang Mustikosari). 
Analisis tuturan:

Kesediaan Sanggoro untuk melamarkan gadis kepada Sidarto tercermin dari tuturannya "aku sing saguh ndhodhog lawange nginang jambe suruhe". Penawaran Sanggoro tersebut dimaksudkan agar Sidarto tidak kecewa, karena dia juga mencintai Endang Mustikosari. Usaha tersebut dilakukan dengan tujuan untuk menghindari terjadinya percekcokan antara dirinya dengan Sidarto, karena hal itu dapat membuat malu keduanya. Untuk itu, Sanggoro menawarkan diri untuk melamarkan wanita lain yang menjadi pilihan adiknya. Penawaran Sanggoro ternyata tidak menarik bagi Sidarto, karena dia juga mencintai Endang Mustikosari. Kata 'matur nuwun' yang dituturkan Sidarto tidak dimaksudkan sebagai tanda setuju atau terima kasih atas penawaran Sanggoro, melainkan untuk menolak penawaran Sanggoro. Karena setelah kata 'matur nuwun', masih diikuti dengan tetap memilih Endang Mustikosari sebagai pilihan hatinya.

\section{Tindak tutur 'Mengancam' dan 'Mendukung'}

Konteks tuturan:

Tumenggung Wiroguno kebingungan dalam menghadapi keteguhan hati rara Mendut, sehingga dia meminta pendapat dari para pembantunya.

Bentuk tuturan:

Wirojoyo:

"Menawi Mendut mboten purun, mopa kapundhut garwa, lha kadhawuhan mbayar pajeg. Mangke dangu-dangu lak nggih purun, saking pundi artanipun Kanjeng"

(Kalau Mendut tidak mau, menolak dijadikan isteri, disuruh membayar pajak. Nanti lama kelamaan khan bersedia, dari mana dia mendapatkan uang kanjeng).

Wiromantri:

"Menika leres, leres ndara nggung.

Kadhawuhan mbayar pajeg kemawon. Leres, leres kanjeng, dangu-dangu lak nggih keluh"

(Itu betul, betul ndara Nggung. Disuruh membayar pajak saja. Betul, betul kanjeng, lama kelamaan juga akan luluh).

Analisis tuturan:

Pendapat yang disampaikan Wirojoyo tersebut bukan merupakan pemberitahuan terhadap rara Mendut, tetapi lebih merupakan ancaman, karena dia akan dibebani untuk membayar pajak. Pajak mestinya hanya dibebankan kepada para pedagang, saudagar, atau bangsawan yang berpenghasilan tinggi, namun kini akan dibebankan kepada Mendut yang tidak mempunyai penghasilan apa-apa. Dengan diwajibkannya Mendut membayar pajak, jelas merupakan ancaman 
bagi Mendut. Dengan demikian, diharapkan Mendut mau menerima pinangan Tumenggung Wiroguno, karena Mendut tidak mungkin mampu membayar pajak. Pendapat Wirojoyo didukung oleh Wiromantri, yang membenarkan pendapat Wirojoyo. Dengan demikian, ancaman yang disampaikan Wirojoyo telah mendapatkan dukungan Wiromantri, dan diharapkan disetujui oleh Tumenggung Wiroguno.

\section{Tindak tutur 'Menegur' dan 'Memarahi'}

Konteks tuturan:

Pembicaraan antara manggalayuda Sudiro dengan ayahnya (Donowilopo) yang membahas tentang keberadaan seorang wanita (Tarkini), yang menolong anaknya (Sutrisno). Karena Tarkini berasal dari desa, maka tindak tanduknya kurang tahu sopan-santun, dan tidak berkenan di hati Manggalayuda Sudiro.

Bentuk tuturan:

M. Sudiro:

"Hus Tarkini !, kowe durung ngerti apa karo aku?"

Tarkini:

(Hus Tarkini !, kamu belum tahu siapa saya ?)

"Jare bapak maratuwa"

(katanya ayah mertua).

M. Sudiro:

"Aku iki Manggalayuda, raja mudha wakil dalem ingkang sinuwun prabu Lesanpuro" (aku ini Manggalayuda, raja muda wakil yang mulia prabu Lesanpuro)

Tarkini:

$$
\begin{aligned}
& \text { "Nggih rak bapakne ........" } \\
& \text { (ya khan bapaknya ........). }
\end{aligned}
$$

Analisis tuturan:

Manggalayuda Sudiro sejak tadi mencoba untuk bersabar, karena menyadari bahwa Tarkini adalah seorang perempuan dari desa yang jauh dari tata krama kerajaan. Namun karena seringnya Tarkini ngelantur, maka Manggalayuda Sudiro berusaha untuk menegurnya dengan mengatakan "hus !". Teguran tersebut dimaksudkan untuk mengingatkan kepada Tarkini agar berhati-hati dalam bertutur kata, karena dia sedang berhadapan dengan seorang raja muda. Pada tuturan yang ke dua, Manggalayuda Sudiro tidak bermaksud untuk 'memberitahukan' bahwa dia seorang raja muda, namun lebih mengandung maksud 'memarahi'. Dengan mengatakan kedudukannya yang terhormat itu, diharapkan Tarkini tidak ngelantur lagi dalam berbicara. Namun dasar anak dari desa yang kurang paham adat istiadat kerajaan, maka Tarkini dengan polosnya tetap mengatakan seperti pada tuturannya yang ke dua. Mestinya bila Tarkini tahu adat 
istiadat kerajaan, maka dia akan segera meminta maaf atas segala tuturannya yang kurang berkenan di hati manggalayuda Sudiro.

\section{SIMPULAN}

Sebuah tuturan tidak mesti memiliki maksud sebagaimana yang dituturkan oleh penutur. Hal ini dapat diamati pada contoh analisis nomor 2, yaitu ketika Bapa Ajar Sidikoro menanyakan tentang jumlah peserta pertemuan kepada cantrik. Ternyata tuturan Bapa Ajar Sidikoro bermakna 'menyuruh', agar cantrik memastikan kelengkapan jumlah peserta pertemuan. Jadi cantrik akan merasa 'tersuruh' untuk melengkapi para peserta pertemuan.

Semua tuturan bila memiliki latar belakang (konteks) tuturan yang berbeda, tentu akan memiliki maksud yang berbeda pula. Misalnya contoh nomor 5, bila konteks tuturannya sedang terjadi peperangan antara dua kerajaan, maka tuturan "he sapa kowe ! ngakua sak durunge tak pateni!" tentu tidak akan bermakna 'menuduh', namun akan bermakna 'menantang'.

Jarak sosial antara penutur dengan mitra tutur akan mempengaruhi model tuturan. Model tuturan orang yang telah 'akrab' akan berbeda dengan model tuturan orang yang 'baru dikenal'. Misalnya dapat diperhatikan pada contoh nomor 3, karena keakraban seorang murid dengan gurunya, maka cukup mengatakan "kula ingkang sowan", daripada "kula nuwun", dalam memberikan salam permisi kepada tuan rumah.

Dengan simpulan tersebut, diharapkan dan disarankan kepada para penulis naskah drama, maupun pemain (khususnya ketoprak) mampu menerapkan kaidah-kaidah pragmatik, selain menerapkan kaidah yang konvensional. Misalnya, dalam membuat dialog yang bermaksud 'menyuruh', maka akan lebih indah dan santun bila direalisasikan dalam bentuk 'meminta tolong', atau bahkan dalam bentuk yang sangat halus yaitu 'memberitahu'. Untuk memahami secara lebih jelas dapat diperhatikan contoh-contoh tuturan berikut (dialog antara seorang Ajar/Guru dengan seorang cantrik/pesuruh);

"Cantrik! tutupen lawang kuwi". (Cantrik !, tutuplah pintu itu). Merupakan tindak tutur 'menyuruh'.

"Cantrik, tulung coba tutupna lawang kae". (Cantrik, tolong tutupkan pintu itu). Contoh tindak tutur 'meminta tolong' untuk menutupkan pintu.

"Cantrik, iki angine kok semribit, aku dadi kademen". (Cantrik, anginnya masuk ke ruangan, aku jadi kedinginan). Contoh tindak tutur 'memberitahu' bahwa pintu tersebut segera harus ditutup agar anginnya tidak masuk, dan membuat kedinginan Bapa Ajar.

Contoh tiga tuturan tersebut menunjukkan tingkat kehalusan dan kesimbolikan dalam bertindak tutur. Tuturan a) bermakna 'menyuruh' secara langsung, yaitu dengan ditandai kata "tutupen" (tutupkan). penambahan 
sufiks -en dalam verba "tutup" bermakna 'menyuruh', seperti banyak dalam verba yang lain, misalnya : jupuken (ambilkan), bukaken (bukakan), gawanen (bawalah), dan sebagainya. Tuturan b) bermakna 'meminta tolong', namun mengandung maksud 'menyuruh', yaitu menyuruh menutup pintu. Tuturan c) bermakna 'memberitahu' bahwa bapa Ajar sedang kedinginan, namun mengandung maksud 'menyuruh' cantrik untuk menutup pintu. Dalam hal ini bapa Ajar tidak bermaksud memberitahu cantrik bahwa dirinya kedinginan, namun lebih diharapkan kepada cantrik untuk segera menutup pintu yang membuat dirinya kedinginan, karena banyaknya angin semribit (angin yang masuk ke ruangan lewat pintu tersebut). Di sini diperlukan kemampuan si cantrik dalam menangkap implikatur dari tuturan bapa Ajar, dan menerjemahkannya dalam tindakan 'menutup pintu'. Jadi model tuturan yang ke tiga inilah yang semestinya diperhatikan oleh para seniman panggung dalam membuat dialog, bukan seperti tuturan yang pertama. Tuturan model yang pertama merupakan bentuk tuturan yang konvensional, tuturan yang ke dua juga masih konvensional, namun lebih halus bentuknya, sedangkan tuturan yang ke tiga merupakan bentuk tuturan yang pragmatik, sekaligus lebih bernuansa simbolik.

Tindak tutur merupakan ungkapan simbolik dari unsur bahasa. Dengan demikian, akan semakin lengkap bila sebuah seni pertunjukan dikemas dengan berbagai unsur simbolik. Dengan memperhatikan kaidahkaidah pragmatik, maka akan diperoleh sebuah pertunjukan seni yang indah dalam berdialog, dan simbolik dalam bertindak tutur, karena simbol merupakan unsur mutlak dalam berkarya seni.

\section{DAFTAR RUJUKAN}

Abdul Syukur Ibrahim.1992. Kajian Tindak Tutur. Surabaya: Usaha Nasional.

Aminuddin. 1983. Semantik: Pengantar Studi tentang Makna. Malang: C.V. Sinar Baru.

Gazdar, G. 1979. Pragmatics: Implicature, Presupposition, and Logical Form. London: Academic Press.

Wijana, I Dewa Putu. 1996. Dasar-dasar Pragmatik. Yogyakarta: Andi Offset.

1999. “Wacana dan Pragmatik”, Dalam Pelatihan Analisis Wacana, Oleh Pusat Penelitian Kebudayaan dan Perubahan Sosial, UGM: 2-7 Agustus 1999.

Kunjana Rahardi, R. 2000. Imperatif dalam Bahasa Indonesia. Yogyakarta: Duta Wacana University Press.

Lakoff, Robin. 1972. Language in Context. New York: Harper and Row.

Leech, Geofrey. 1983. The Principles of Pragmatics. London: Longman.

Levinson, Stephen, C. 1983. Pragmatics., New York: Cambridge University Press. 
Noeng Muhadjir. 1990. Metode Penelitian Kualitatif. Yogyakarta: Rake Surasin.

Soeseno Kartomohardjo. 1993. 'Analisis Wacana dengan Penerapannya pada Beberapa Wacana'. Jakarta: UNIKA Atmajaya.

Sri Murniati D. 1996. 'Cerita Panji dalam Ketoprak' (Skripsi tidak diterbitkan). Jakarta: F. Sastra, Universitas Indonesia.

Sudyarsono, HK. 1985. Ketoprak Kelilingan dalam Gamelan, Dramatari, dan Komedi Jawa. Jakarta: Dept. Pendidikan dan Kebudayaan. . 1990. Unggah-ungguh Basa ing Ketoprak. Jakarta: Dept. Pendidikan dan Kebudayaan.

Sumarlam. 1999. 'Ke Arah Pemahaman dan Kajian Pragmatik' (dalam Haluan Sastra Budaya, No. 37, Th. XVIII, Januari, 1999), Surakarta: Universitas Sebelas Maret. 